\title{
Research on the Information Resources Integration Based on the Big Data Technology
}

\author{
Yi Li, HaiYun Xiang, TingTing Zeng \\ (Southwest Petroleum University, Chengdu, Sichuan Province, China, 610500)
}

Keywords: Big data, Information resources, Resources integration

\begin{abstract}
Big data technology can integrate the mass data in some certain ways to unearth products and services of huge values to promote the economic and social change. This paper analyzes the characteristics of the information resources in the era of big data, points out the necessity of information resources integration and explores the integration models of information resources of government and enterprise based on big data technology to provide some references for the relevant researchers.
\end{abstract}

\section{Introduction}

The concept of the integration of information resources can be understood in two aspects: narrow sense and broad sense. From the narrow sense, it refers the original discrete, heterogeneous, distributed and diversified information resources through the logical or physical organization as a whole, which is conducive to the management and service. The concept of the integration of information resources in broad sense is to centralize the scattered resources, to make the unordered resources orderly, and to make them convenient for users. It includes the process of information collection, organization, processing and service. The integration of information resources is a management mode of information resources. Integration is a kind of management, its management philosophy is to replace the past simple information technology information management, information resources should be advocated for use of technology, economy and culture means the overall planning, comprehensive management. The integration of information resources is also a service mode of information resources. Big data technology is the need of information system business development, a series of new application technology based on database system technology and gradually independent. Large data can collect information from multiple information sources. According to the needs of the analysis model, the data is extracted, processed and integrated into integrated data, stored in a unified way. And this data is constantly loaded and updated over time. As a solution to the integration of information resources, big data technology is not a simple fusion of data. Large data technology will be located in different fields, different platforms, different structures of the data extraction, screening, organization and get new data sets.

\section{Necessity of Information Resources Integration}

Both the government and enterprises need to build information platform and integrate information resources to make full use of information resources. The construction of information platform is a systematic project with strong comprehensiveness and high degree of sharing of data. In recent years, enrollment and employment, student management, financial management and other aspects of building their own information systems, but these systems "lack of coordination", resulting in a large number of information island, information resources cannot be effectively led to massive data flow, no further effective application. In the era of big data, in the face of massive data generated by various information systems, storage, integration and analysis of large data, integration and use of information become the key issues that need to be resolved in the construction of information platform. It puts forward new requirements for the construction of information platform, and needs to integrate the information resources of each platform. Establish a unified information data standard. Further increase the intensity of information construction. This requires departments in the 
construction and integration of information platform, must work together, follow the unified standards, to ensure that the platform construction is standardized and orderly, to achieve massive data sharing. We want to establish a unified application system standard. Make overall plan of system platform construction, carry out new system development and old system integration in accordance with unified standard, so as to realize the rational separation and structure of information platform. Emphasis on data security management, to ensure large data ecosystem, information security, big data era, the interconnection between information systems is inevitable, they will form a closely related ecosphere. In this life circle, the large amount of data stored and managed is the core of the enterprise's market competition, and it needs to control and manage the data security. Therefore, enterprises should be based on the premise of data security management in the information resources integration process, need to carry out extensive cooperation with upstream and downstream enterprises and the safety management mechanism, evaluation mechanism and three party institutions, from the enterprise management system, process and technical means and other aspects to ensure data security big data ecosystem. We establish a unified digital resource integration standard. The information platform includes the basic hardware platform, network infrastructure platform and application software. It focuses on the integration of digital resources, integrates and provides valuable information for management and decision-making.

\section{Resources Integration of Government Information Based on the Big Data Technology}

Common Problems of Information Resources Integration of Government. After the development in the recent years, our government has made great progress in information technology. As the core resource of e-government, the value of information resources is gradually highlighted. However, at present, the management of information resources is mainly driven by events at all levels of governments in all parts of china. The related data integration and sharing work has fallen into a predicament, which has not formed a long-term mechanism, and has continuously promoted the integration and application of government information resources. At present, in most parts of the country, the government's economic and Information Committee is responsible for the management of information resources. Some are responsible for the establishment of specialized agencies and management, while others are responsible for specific departments. There is no unified leadership system for the management of government information resources in China, and the corresponding management responsibilities and management standards have not been improved yet. This will inevitably lead to the difficulty of integration and utilization of government information resources, and the effect will be difficult to guarantee. The data format is not uniform, and the data is repeated and even inconsistent in different business systems, which results in the consistent segmentation and disruption of the business process. Secondly, the organization and classification of information resources is irrational, which leads to low utilization of information resources. Finally, due to the lack of uniform data standards, many information resources are still unable to integrate and share. In addition, in the process of the integration of information resources, it is also difficult to integrate the old and new information systems. The information system of different departments by the application of database operating system different from the host, even different networks, and information resources more and more resources, more and more abundant species, resulting in more and more diversified information resource system. These problems have hindered the efficiency of government coordination and the improvement of public service. They also restricted the development of e-government.

Countermeasures of Information Resources Integration of Government Based on the Big Data Technology. Make full use of government information resources based on data integration platform, guided by the market, to the application for the driver, the actual need to grasp the economic and social development, to develop to meet the information content and service diversification and multi-level demand. It is urgent to select the application requirements first, and the application of some government information resources fields with relatively obvious performance. At the same time, it is necessary to establish an operational mechanism that conforms to the market rules and provides 
practical guarantee for the commercialization of information resources integration and the industrialization of application services. Based on the construction of all kinds of data resources, should focus on the construction of data exchange service system, directory management service system, data integration and service system, operation management system, service interface and service system and platform system application platform for the integration of government information resources. The data exchange service system is used to realize the unified exchange of all kinds of information resources, and requires the synchronous updating of all kinds of database contents. The data integration service system can dynamically configure and realize the database needed for various business applications through data cleaning, transformation, association and integration. The construction of directory management service system focuses on the exchange, interaction, inquiry, statistics and dynamic permission level setting of various information resources. The function of operation management service system is to unify all kinds of applications and users. The interface and service system provides interface services for application developers and business application integration. Platform portal system is the window of external information display of government information platform. On the one hand, the development and utilization of government information resources is the core content of e-government construction. It is also a construction of basic information facilities. Therefore, it is necessary to rely on the government's capital investment. On the other hand, the development and utilization of commerce can promote the information resources that the government has mastered through intensive processing, association and integration, and eventually make use of it in a more convenient, more acceptable and more flexible form. This broadens the channels for public access to government information. In addition, the extensive integration and sharing of government information resources also stimulated the society's demand for all kinds of information products processed deeply. With the continuous upgrading of the information needs of society, the products formed by commercial development will be more widely accepted and used.

\section{Resources Integration of Enterprise Information Based on the Big Data Technology}

Common Problems of Information Resources Integration of Enterprise. Enterprise information resources are in extensive management for a long time. Enterprises have a large amount of data and information on the internal external feedback is only stored, screening, classification, integration and processing of the lack of information, rarely use the information management and decision-making, information resource utilization rate is very low. Most enterprises lack effective methods, means and mechanisms to manage the information resources. They cannot extract, integrate and analyze the information resources in a timely and effective way, and the integration is very low. As for enterprises, the core goal of information resource management is to ensure the effective use of information resources and make correct decisions. The difficulty of the only depth cognition characteristics of large data and big data brings to the enterprise information resource management, in order to organize and manage complex structure, a large number of real-time and high potential data information, can timely and accurately analyzing the potential value of massive data, in order to ensure the effective use of information resources. However, most enterprises in the information resources management process, the perception of big data is only superficial, leading to the effective utilization of information resources on the low side. Data management is a relatively new development concept, with the rapid development of a new generation of information technology, the enterprise data quality requirements more and more high, enterprises need to output data governance rules with high reliability of data. However, most domestic enterprises in the data management is still at the primary stage, just do a simple data quality check, data archiving, data security etc. scattered data processing work, no data management methodology, data as the core assets operating philosophy has not yet formed, lack of construction data management integrated system.

Countermeasures of Information Resources Integration of Enterprise Based on the Big Data Technology. Enterprise information resource platform is a professional system, which embodies the basic process and characteristics of enterprise intelligence work. At the same time, as a computer 
system, the implementation phase must include requirements design, architecture design, database design, process design, functional design, interface design, detailed design and so on. Based on the specialization of enterprise information resource platform in functional design and the complexity of technology implementation, the requirements of platform design and implementation personnel are very high. And the enterprise is not only familiar with professional and intelligence services, but also familiar with the design of computer systems complex talent shortage. Complex functions, long construction period and lack of professionals are the biggest difficulties encountered during the integration of enterprise information resources. In the era of big data, the scientific and effective management of massive and complex data of enterprises is the prerequisite to ensure the potential value of large data technology to fully tap the potential of enterprise information resources. Paper information and digital video, audio, e-mail, pictures and other unstructured data in the enterprise information resources in the proportion of the gradual rise, which contains a wealth of potential value. The construction methods of these unstructured data are high repetition rate, redundant storage, and complex relationships between different objects. However, the traditional object-oriented data model cannot achieve the organization and management of unstructured data. The application system is the foundation of big data, enterprises should increase data technology deployment efforts, big data technology integrated use of cloud computing, distributed computing, data exchange, data warehouse, data mining and unstructured data processing and other levels to build a big data platform. Therefore, the enterprise needs to promote the integration development of structured and unstructured data, hypertext, hypermedia data model and the integration of object-oriented data model, builds the data model for structured and unstructured data unified organization and management. In the era of big data, the ultimate goal of the integration of enterprise information resources is to make use of big data analysis and mining technology to achieve efficient use of information resources.

\section{Conclusion}

Big data is of great significance in the integration of information resources. The integration of information resources can dig out huge data value and make full use of it in the massive miscellaneous information resources. The integration of government and enterprise information resources is conducive to better use of the efficiency of information resources to support the decision-making activities of the government and enterprises. Organizations from all walks of life must follow the development of society and guide the construction and service of information resources based on the big data technology.

\section{References}

[1] Huang He, Su Huanqun, He Lian, Zheng Lirong, Economic benefits of developing and sharing medical information resources in big data environment [J]. Chinese Journal of Medical Library and Information Science, 2016, 25(8): 70-72.

[2] Wang Xianyan, Information Resource Construction and Service of University Library in big data Environment [J]. Journal of Library and Information Sciences in Agriculture, 2015, 27(10): 26-28.

[3] Yao Guozhang, Liu Zhongxiang, The integration and utilization of government information resources in the background of big data [J]. Journal of Nanjing University of Posts and Telecommunications (Social Science), 2015, 17(4): 20-25.

[4] Qiang Dongqiang, Proposition to Build the Colleges Information Resources Libraries in the Environment of Big Data, Journal of Jixi University, 2016, 16(5): 39-42. 